\title{
Effects of different hormonal treatments on growth parameters and secondary metabolite production in organ culture of Hyssopus officinalis L.
}

\author{
Hanieh MohaJjel Shoja *, Hengameh KharRati Shishavan \\ Department of Plant Biology, Faculty of Natural Sciences, University of Tabriz, Tabriz, Iran
}

\begin{abstract}
Hyssopus officinalis L. is a medicinal plant containing valuable phytochemicals and is used extensively in the pharmaceutical industry. As this plant naturally contains low levels of these metabolites, plant cell and tissue culture technologies are used to produce them in large volumes. The present study aimed first to evaluate the effects of different types of cytokinins, including benzyl adenine (BA), kinetin (KIN), and thidiazuron (TDZ), at $1 \mathrm{ppm}$ concentration in the culture medium on growth parameters and production of secondary metabolites and photosynthetic pigments in organ culture of $H$. officinalis; in the second step, the study investigated the effect of different concentrations $(0,0.2,1,1.5$, and $2 \mathrm{ppm})$ of the most effective type of cytokinin. The results showed that TDZ was the optimal type of growth regulator compared to BA and KIN as it showed a positive influence on the studied traits; furthermore, its highest concentration of $2 \mathrm{ppm}$ in culture medium was determined to be the best one that enabled the highest production of secondary metabolites and photosynthetic pigments. We conclude that the presence of growth regulators can strongly influence the growth and development of plants in tissue culture conditions.
\end{abstract}

Key words: growth parameters, Hyssopus officinalis, photosynthetic pigment, secondary metabolite, thidiazuron

\section{Introduction}

Since ancient times, plants have been used as sources of natural drugs to treat various diseases. It has been reported that over $60 \%$ of anticancer drugs and $75 \%$ of drugs for treating infectious diseases are derived from plants or are analogs of plant compounds (Anand et al., 2019). Medicinal importance of plants depends on the presence of a large group of low-molecular-weight organic compounds known as secondary metabolites that are available in very low quantities (less than $1 \%$ of dry weight of plants). These metabolites are categorized as phenolic acids, flavonoids, alkaloids, glycosides, tannins, lignans, and essential oils and are involved in plant protection against herbivores, as an attractant of pollinators, and in plant symbiosis with microorganisms (Chitra et al., 2019). The production of these compounds may be limited to a particular plant family, genus, or even a particular species. One of the most widely used herbal plants in Iran is Hyssopus officinalis (family Lamiaceae), which is used as expectorant, antiseptic compound, tonic, and cough reliever due to the presence of some secondary metabolites such as flavonoids, tannins, diosmin, pinocamphone, $\alpha$-and $\beta$-pinene, and sesquiterpenes (Bernáth, 1993; Fathiazad and Hamedeyazdan, 2011). To achieve a high level of production of valuable secondary metabolites, plant cell and tissue culture technique is considered as a powerful method that could enable to control the factors that affect the synthesis and/or accumulation of these metabolites (Chitra et al., 2019). Manipulating the amount of plant growth regulators in the culture medium is an important strategy for inducing these metabolites (Fathiazad and Hamedeyazdan, 2011). Cytokinins are among the plant growth regulators that induce the production of secondary metabolites in

\footnotetext{
* Corresponding author: Department of Plant Biology, Faculty of Natural Sciences, University of Tabriz, Tabriz, Iran 5166616471; e-mail: mohajelh@yahoo.com
} 
in vitro cultures of several medicinal plants such as Salvia miltiorrhiza, Sibylum marianum L. Gaertn., Lallemantia iberica, Scutellaria alpine, and Artemisia annua (Gupta et al., 2011; Khan et al., 2014; Pourebad et al., 2015). Because of the pharmacological importance of $H$. officinalis and because only few reports are available for in vitro regeneration of this plant, the present study aimed to compare, in the first step, the effect of different types of cytokinins (adenine-type and phenylurea-type), including kinetin (KIN), 6-benzylaminopurine (BA), and thidiazuron (TDZ), on the production of total phenol and flavonoids, the content of photosynthetic pigments, and some growth parameters of this plant, and, in the second step, to determine the effect of different concentrations of the most effective phytohormone on the abovementioned parameters.

\section{Materials and methods}

\section{Plant material}

The seeds of $H$. officinalis $\mathrm{L}$. were obtained from Department of Plant Eco-physiology, Faculty of Agriculture, University of Tabriz, Iran. The mature seeds were disinfected with $70 \%(\mathrm{v} / \mathrm{v})$ ethanol for $3 \mathrm{~min}$ and $5 \%(\mathrm{v} / \mathrm{v})$ sodium hypochlorite for $15 \mathrm{~min}$ and were washed using sterile distilled water. The disinfected seeds were cultured on basal MS medium without growth regulators (Murashige and Skoog, 1962).

\section{Explant preparation, shoot formation, and growth parameter determination}

The media containing seeds were kept in a growth chamber (Conviron PGR15, Winnipeg, MB, Canada) with the daily photoperiod of $16 \mathrm{~h}$ light/ $8 \mathrm{~h}$ dark, $200 \mu \mathrm{mol} \cdot \mathrm{m}^{-2} \cdot \mathrm{s}^{-1}$ photosynthetic photon flux density, and a constant temperature of $24 \pm 1^{\circ} \mathrm{C}$. After obtaining the seedlings, the nodal segments were cut and placed on MS media containing different growth regulators, namely TDZ (Sigma, P6186), BA (Sigma, B3274), and KIN (Sigma K0753), at the concentration of $1 \mathrm{ppm}$ or at different concentrations $(0,0.2,1,1.5$, and $2 \mathrm{ppm})$ of TDZ (Figs. 1A-D). Each treatment was performed in triplicate with 5 to 8 explants per medium. After 5 weeks, the number of leaves, number of shoots and roots, number of nodes, length of shoots and roots $(\mathrm{cm})$, and fresh weight $(\mathrm{FW}, \mathrm{g})$ of the regenerated plants were determined.

\section{Extraction of photosynthetic pigments}

Photosynthetic pigments were extracted using the method of Wellburn (Wellburn, 1994). After 5 weeks of culture, $0.2 \mathrm{~g}$ of regenerated plants were grinded in $2 \mathrm{ml}$ of $100 \%$ dimethyl sulfoxide and centrifuged at $13000 \mathrm{rpm}$ for 15 min (Spectrafuge 24D), Bioseb, Vitrolles, France). The supernatants were collected, and the absorbance was measured at 665,649 , and $480 \mathrm{~nm}$ for chlorophyll $a$, chlorophyll $b$, and carotenoids, respectively, by using a spectrophotometer. The concentrations of chlorophyll $a\left(\mathrm{C}_{\mathrm{a}}\right)$, chlorophyll $b\left(\mathrm{C}_{\mathrm{b}}\right)$, and carotenoids $\left(\mathrm{C}_{\mathrm{X}+\mathrm{C}}\right)$ were calculated as mg of pigments per $\mathrm{g}$ of $\mathrm{FW}$ using the following formula:

$$
\begin{gathered}
\mathrm{C}_{\mathrm{a}}=12.19 \mathrm{~A}_{665}-3.45 \mathrm{~A}_{649} \\
\mathrm{C}_{\mathrm{b}}=21.99 \mathrm{~A}_{649}-5.32 \mathrm{~A}_{665} \\
\mathrm{C}_{\mathrm{X}+\mathrm{C}}=\left(1000 \mathrm{~A}_{480}-1.14 \mathrm{C}_{\mathrm{a}}-70.16 \mathrm{C}_{\mathrm{b}}\right) / 220
\end{gathered}
$$

\section{Extraction of secondary metabolites}

After 5 weeks of culture, shoots obtained from the nodal explants were dried in an oven at $35^{\circ} \mathrm{C}$ for $24 \mathrm{~h}$. To extract phenolic and flavonoid compounds, $0.2 \mathrm{~g}$ of plant material was crushed in $2 \mathrm{ml}$ of $99.9 \%$ methanol. The extracts were centrifuged at $13000 \mathrm{rpm}$ for $10 \mathrm{~min}$, and the supernatants were collected for the next experiment. Total phenolic content in each extract was determined by Folin-Ciocalteu reagent. Methanolic extracts $(100 \mu \mathrm{l})$ were mixed with $2.5 \mathrm{ml}$ deionized water and $100 \mu \mathrm{l}$ of Folin-Ciocalteu reagent. After $6 \mathrm{~min}, 150 \mu \mathrm{l}$ of sodium carbonate solution was added to the mixture. The absorption was measured at $760 \mathrm{~nm}$ after $30 \mathrm{~min}$. The results were expressed as mg of pyrogallol per $\mathrm{g}$ of dry weight (DW). To estimate the total flavonoid content, $0.5 \mathrm{ml}$ of methanolic extracts was mixed with $2.5 \mathrm{ml}$ of deionized water and $150 \mu \mathrm{l}$ of $5 \%(\mathrm{w} / \mathrm{v})$ sodium nitrate solution. After $6 \mathrm{~min}, 300 \mu \mathrm{l}$ of $10 \%(\mathrm{w} / \mathrm{v})$ aluminum chloride was added. After $5 \mathrm{~min}, 1 \mathrm{ml}$ of $1 \mathrm{M}$ sodium hydroxide was added to the mixture. The absorbance was measured at $510 \mathrm{~nm}$ using a spectrophotometer. Flavonoid contents were expressed as $\mathrm{mg}$ of quercetin per $\mathrm{g}$ of $\mathrm{DW}$.

\section{Statistical analysis}

Experiments were performed in a completely randomized design in a triplicate for each treatment. The data were analyzed using GraphPad prism 6 software. Oneway ANOVA and Duncan's multiple range test were used 


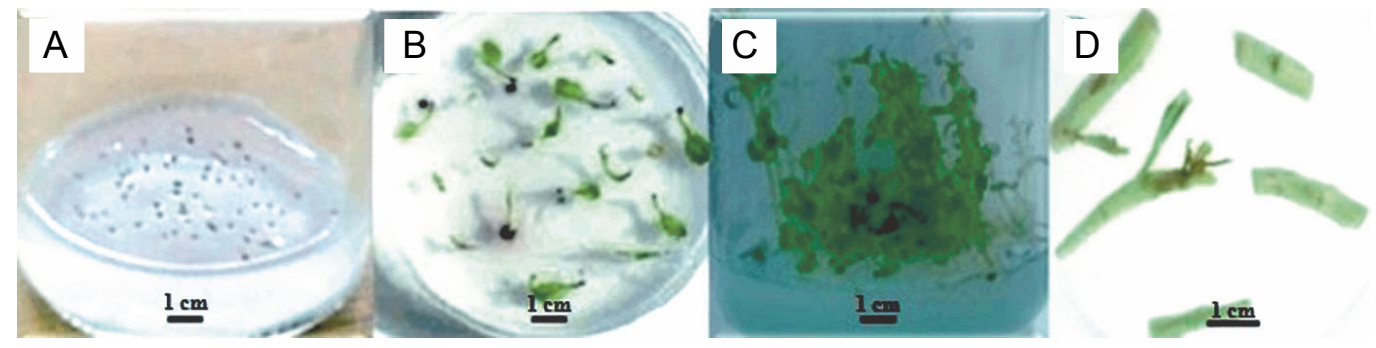

Fig. 1. Seeds germination on basic MS agar medium (A, B and C) and the nodal segments on differents hormonal containing media (D)

to compare mean $\pm \mathrm{SD}$ between the groups. $P<0.05$ was considered to be statistically significant.

\section{Results}

\section{Effect of different cytokinins on the growth parameters of seedlings}

In Figure 2, the effect of different hormonal treatments on growth parameters of 5 -week-old seedlings is presented. As shown in this figure, TDZ supplementation exhibited a significant increase only in the number of leaves $(+82.1 \%, P<0.05)$, and all other parameters (number of shoots, roots, and nodes) were decreased in the presence of this hormone. BA and KIN negatively affected the abovementioned parameters (Fig. 1A). The lengths of shoots and roots were significantly decreased after BA $(-68.68 \%$ and $-98.41 \%, P<0.05$, respectively), KIN $(-18.52 \%$ and $-78.16 \%, P<0.05$, respectively), and TDZ $(-17.09 \%$ and $-76.05 \%, P<0.05$, respectively) treatments (Fig. 2B), and the fresh weights of explants were increased only in those grown on TDZ-containing media $(+22.71 \%, P<0.05)$ (Fig. 2 C, Tables 1,2 , and 3$)$.

\section{Effect of different cytokinins on total phenolic and flavonoid content of seedlings}

Figure 3 and Table 4 present the effects of $1 \mathrm{ppm}$ of hormonal treatments on total phenolics and flavonoid contents. Flavonoid content was significantly increased after BA $(+102.05 \%, P<0.05)$, KIN $(+42.66 \%, P<0.05)$, and TDZ $(+207.69 \%, P<0.05)$ treatments as compared to control. Similar results were also obtained for total phenolic content for BA $(+42.16 \%, P<0.05)$, KIN $(+27.04 \%$, $P<0.05)$, and TDZ $(+45.87 \%, P<0.05)$ treatments.

\section{Effect of different cytokinins on the production of photosynthetic pigments in seedlings}

As shown in Figure 4 and Table 5, TDZ exhibited the most positive effect on the production of photosynthetic

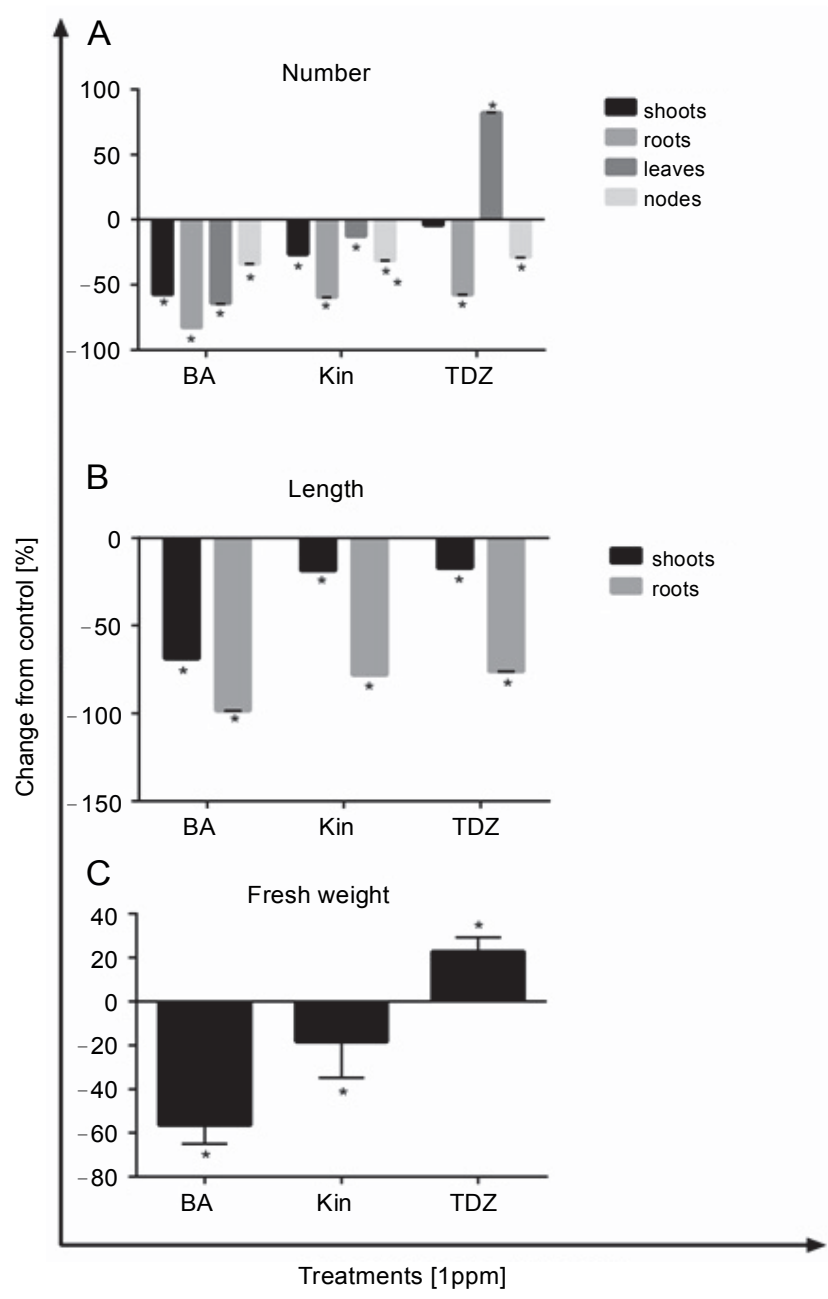

Fig. 2. Effect of different hormonal treatments (ppm) on the number of A) shoots, roots, leaves and nodes, B) length of shoot and roots, $\mathrm{C}$ ) and fresh explants weight $(P<0.05$ versus control)

pigments, including chlorophyll $a(+546.42 \%, P<0.05)$, chlorophyll $b(+1211.11 \%, P<0.05)$, and carotenoids $(+740 \%, P<0.05)$ as compared to control. Additionally, KIN supplementation also increased chlorophyll $b$ production $(+144.4 \%, P<0.05)$ as compared to control. 
Table 1. Effect of different hormonal treatments (ppm) on the number of shoots, roots, leaves and nodes of Hyssopus officinalis L.

\begin{tabular}{c|c|c|c|c}
\hline Hormones & Shoots & Roots & \multicolumn{1}{c|}{ Leaves } & Nodes \\
\hline MS & $5.002 \pm 0.80$ & $2.73 \pm 0.06$ & $15.26 \pm 0.24$ & $1.02 \pm 0.22$ \\
\hline BA & $2.14 \pm 0.24$ & $0.47 \pm 0.04$ & $5.47 \pm 0.64$ & $0.67 \pm 0.20$ \\
\hline KIN & $3.67 \pm 0.12$ & $1.01 \pm 0.05$ & $13.35 \pm 0.01$ & $0.70 \pm 0.10$ \\
\hline TDZ & $4.80 \pm 0.34$ & $1.16 \pm 0.06$ & $27.80 \pm 0.34$ & $0.73 \pm 0.34$ \\
\hline
\end{tabular}

Data are presented as mean \pm standard division (SD); MS - Murashige and Skoog medium; BA - benzyl adenine; KIN - Kinetin; TDZ - Thidiazuron

Table 2. Effect of different hormonal treatments (ppm) on the length of shoot $(\mathrm{cm})$ and roots $(\mathrm{mm})$ of Hyssopus officinalis L.

\begin{tabular}{c|c|c}
\hline \multirow{2}{*}{ Hormones } & \multicolumn{2}{|c}{ Length } \\
\cline { 2 - 3 } & shoots [cm] & roots [mm] \\
\hline MS & $3.86 \pm 1.06$ & $8.06 \pm 0.24$ \\
\hline BA & $1.21 \pm 0.41$ & $0.128 \pm 0.04$ \\
\hline KIN & $3.145 \pm 0.02$ & $1.76 \pm 0.03$ \\
\hline TDZ & $3.20 \pm 0.30$ & $1.93 \pm 0.06$ \\
\hline
\end{tabular}

Data are presented as mean \pm standard division (SD); MS - Murashige and Skoog medium; BA - benzyl adenine; KIN - Kinetin; TDZ - Thidiazuron

Table 3. Effect of different hormonal treatments (ppm) on fresh explants weight of Hyssopus officinalis L.

\begin{tabular}{c|c}
\hline Hormones & $\begin{array}{c}\text { Fresh weight } \\
{[\mathrm{mg}]}\end{array}$ \\
\hline MS & $75.46 \pm 6.41$ \\
\hline BA & $32.96 \pm 8.52$ \\
\hline KIN & $61.70 \pm 16.54$ \\
\hline TDZ & $92.60 \pm 6.58$ \\
\hline
\end{tabular}

Data are presented as mean \pm standard division (SD); MS - Murashige and Skoog medium; BA - benzyl adenine; KIN - Kinetin; TDZ - Thidiazuron

\section{Effects of different TDZ concentrations on the growth parameters of seedlings}

According to the abovementioned results, TDZ was determined as the optimal type of growth regulator as compared to BA and KIN. Therefore, its different concentrations $(0.2,1,1.5$, and $2 \mathrm{ppm})$ were evaluated to achieve the best culture medium conditions. The results showed that the maximum number of leaves was obtained in $1 \mathrm{ppm}$ of TDZ $(+108.3 \%, P<0.05)$, although the concentrations of $1.5(+87.15 \%, P<0.05)$ and $2 \mathrm{ppm}$ $(+71.76 \%, P<0.05)$ also had a positive effect on this

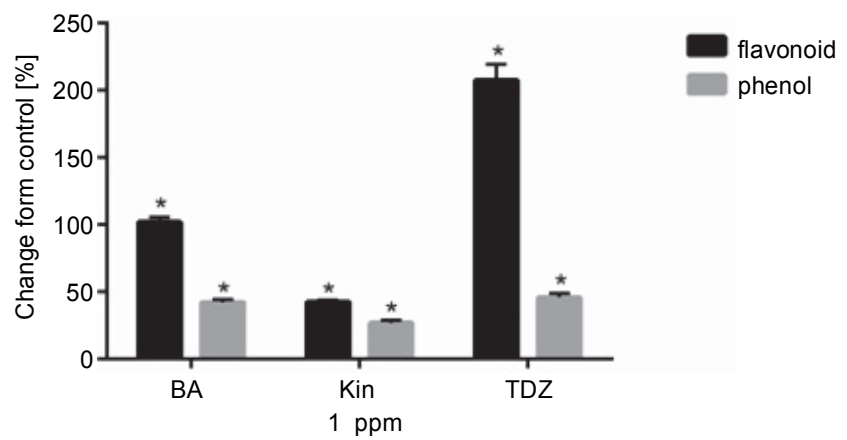

Fig. 3. Effect of different hormonal treatments (ppm) on total flavonoid (mg QE/g) and phenol (mg PYRO/g) content $(P<$ 0.05 versus control)

Table 4. Effect of different hormonal treatments (ppm) on total flavonoid (mg QE/g) and phenol (mg PYRO/g) content of Hyssopus officinalis L.

\begin{tabular}{c|c|c}
\hline Hormones & $\begin{array}{c}\text { Flavonoid } \\
{[\mathrm{mg} \mathrm{QE} / \mathrm{g}]}\end{array}$ & $\begin{array}{c}\text { Phenol } \\
{[\mathrm{mg} \text { PYRO/g] }}\end{array}$ \\
\hline $\mathrm{MS}$ & $125.33 \pm 8.59$ & $63.63 \pm 2.20$ \\
\hline $\mathrm{BA}$ & $253.23 \pm 3.63$ & $90.46 \pm 2.03$ \\
\hline $\mathrm{KIN}$ & $178.80 \pm 1.11$ & $80.84 \pm 2.11$ \\
\hline $\mathrm{TDZ}$ & $385.63 \pm 11.85$ & $92.82 \pm 3.13$ \\
\hline
\end{tabular}

Data are presented as mean \pm standard division (SD); MS - Murashige and Skoog medium; BA - benzyl adenine; KIN - Kinetin; TDZ - Thidiazuron

parameter (Fig. 5A). In all concentrations of TDZ, the length of roots decreased significantly, whereas shoot length decreased at $2 \mathrm{ppm}$ concentration $(-73.07 \%$, $P<0.05)$ (Fig. 5B). Fresh weight of explants increased remarkably at the concentration of $2 \mathrm{ppm}(+531.24 \%$, $P<0.05$ ) (Fig. 5C, Tables 6, 7, and 8).

\section{Effect of different TDZ concentrations on total phenolics and flavonoid content of seedlings}

According to the obtained results, a positive correlation was observed between the contents of total phenolics 
Table 5. Effect of different hormonal treatments (1ppm) on photosynthetic pigments production of Hyssopus officinalis L.

\begin{tabular}{c|c|c|c}
\hline Hormones & $\begin{array}{c}\text { Chlorophyll } a \\
{[\mathrm{mg} / \mathrm{g}]}\end{array}$ & $\begin{array}{c}\text { Chlorophyll } b \\
{[\mathrm{mg} / \mathrm{g}]}\end{array}$ & $\begin{array}{c}\text { Carotenoid } \\
{[\mathrm{mg} / \mathrm{g}]}\end{array}$ \\
\hline $\mathrm{MS}$ & $0.28 \pm 0.002$ & $0.18 \pm 0.004$ & $0.05 \pm 0.001$ \\
\hline $\mathrm{BA}$ & $0.36 \pm 0.003$ & $0.25 \pm 0.002$ & $0.02 \pm 0.003$ \\
\hline $\mathrm{KIN}$ & $0.28 \pm 0.008$ & $0.44 \pm 0.02$ & $0.04 \pm 0.002$ \\
\hline TDZ & $1.81 \pm 0.002$ & $2.36 \pm 0.03$ & $0.42 \pm 0.005$ \\
\hline
\end{tabular}

Data are presented as mean \pm standard division (SD); MS - Murashige and Skoog medium; BA - benzyl adenine; KIN - Kinetin; TDZ - Thidiazuron

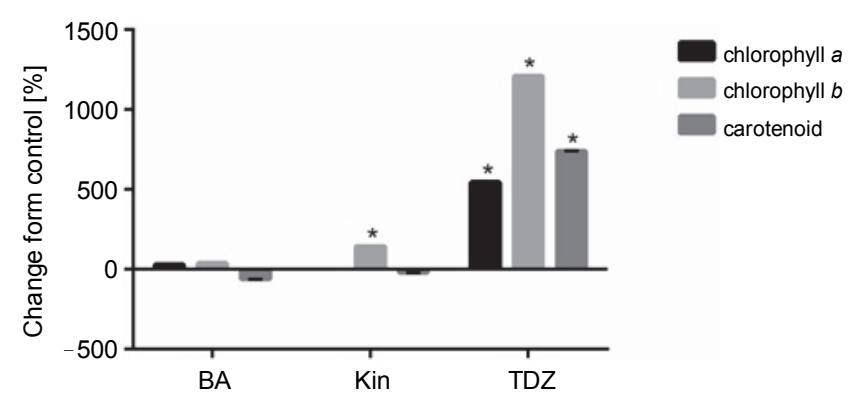

Fig. 4. Effect of different hormonal treatments (ppm) on photo synthetic pigments production $(P<0.05$ versus control)

and flavonoids with an increasing TDZ concentration in growth medium; the highest contents of phenolics $(+542.12 \%, P<0.05)$ and flavonoids $(+237.42 \%, P<0.05)$ were obtained at $2 \mathrm{ppm}$ concentration of TDZ (Fig. 6 , Table 9).

\section{Effect of different TDZ concentrations on photosynthetic pigment production in seedlings}

Figure 7 and Table 10 present the effect of different concentrations of TDZ on chlorophyll $a$, chlorophyll $b$, and carotenoid production. As shown in the figure, TDZ at $2 \mathrm{ppm}$ concentration had the best effect on chlorophyll $a(+850 \%, P<0.05)$, chlorophyll $b(+359.09 \%$, $P<0.05)$, and carotenoid ( $+900 \%, P<0.05)$ production; however the concentrations of 1 and $1.5 \mathrm{ppm}$ were also found to be the effective concentrations that influenced these parameters.

\section{Discussion}

Growth regulators have a remarkable effect on the development of explants in tissue culture. Different experiments have proven a significant influence of cytokinins on the growth rate and multiplication of explants (Khan et al., 2014; Siddique et al., 2015). H. officinalis is

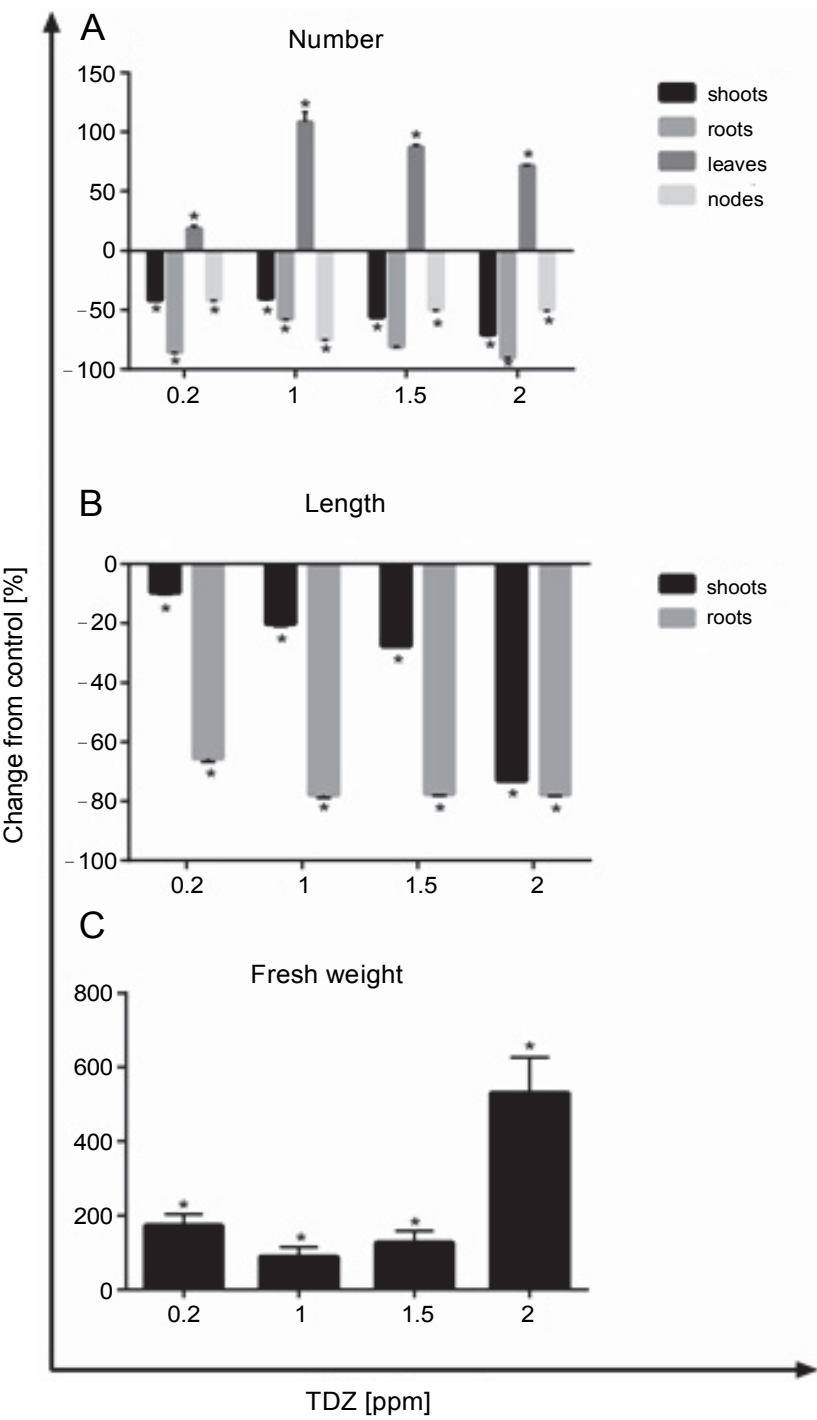

Fig. 5. Effect of different concentrations of TDZ on growth parameters $(P<0.05$ versus control)

a pharmacologically important plant, and very few reports are available on its in vitro regeneration; therefore, the present study evaluated the effects of different cyto- 
Table 6. Effect of different concentrations (0, 0.2, 1, 1.5 and $2 \mathrm{ppm})$ of TDZ on the number of shoots, roots, leaves and nodes of Hyssopus officinalis L.

\begin{tabular}{c|c|c|c|c}
\hline $\begin{array}{c}\text { TDZ concentration } \\
{[\mathrm{ppm}]}\end{array}$ & Shoots & Roots & Leaves & Nodes \\
\hline 0 & $5.31 \pm 0.57$ & $3.24 \pm 1.16$ & $13.00 \pm 1.52$ & $4.00 \pm 0.57$ \\
\hline 0.2 & $3.10 \pm 0.16$ & $0.47 \pm 0.35$ & $15.42 \pm 2.51$ & $2.33 \pm 0.33$ \\
\hline 1 & $3.17 \pm 1.00$ & $1.38 \pm 0.62$ & $27.08 \pm 8.50$ & $1.00 \pm 0.10$ \\
\hline 1.5 & $2.33 \pm 0.33$ & $0.62 \pm 0.26$ & $24.33 \pm 2.18$ & $2.00 \pm 0.10$ \\
\hline 2 & $1.55 \pm 0.87$ & $0.32 \pm 0.18$ & $22.33 \pm 0.33$ & $2.00 \pm 0.57$ \\
\hline
\end{tabular}

Data are presented as mean \pm standard division (SD)

Table 7. Effect of different concentrations $(0,0.2,1,1.5$ and $2 \mathrm{ppm})$ of $\mathrm{TDZ}$ on the length of shoot $(\mathrm{cm})$ and roots $(\mathrm{mm})$ of Hyssopus officinalis $\mathrm{L}$.

\begin{tabular}{c|c|c}
\hline \multirow{2}{*}{$\begin{array}{c}\text { TDZ concentration } \\
{[\mathrm{ppm}]}\end{array}$} & \multicolumn{2}{|c}{ Length } \\
\cline { 2 - 3 } & shoots [cm] & roots [mm] \\
\hline 0 & $4.16 \pm 1.50$ & $10.54 \pm 2.86$ \\
\hline 0.2 & $3.76 \pm 0.68$ & $3.62 \pm 0.96$ \\
\hline 1 & $3.32 \pm 0.89$ & $2.32 \pm 0.88$ \\
\hline 1.5 & $3.01 \pm 0.35$ & $2.37 \pm 0.49$ \\
\hline 2 & $1.12 \pm 0.15$ & $2.34 \pm 0.46$ \\
\hline
\end{tabular}

Data are presented as mean \pm standard division (SD)

Table 8. Effect of different concentrations $(0,0.2,1,1.5$ and $2 \mathrm{ppm})$ of TDZ on fresh explants weight of Hyssopus officinalis L.

\begin{tabular}{c|c}
\hline $\begin{array}{c}\text { TDZ concentration } \\
{[\mathrm{ppm}]}\end{array}$ & $\begin{array}{c}\text { Fresh weight } \\
{[\mathrm{mg}]}\end{array}$ \\
\hline 0 & $64.66 \pm 5.58$ \\
\hline 0.2 & $176.38 \pm 30.59$ \\
\hline 1 & $122.38 \pm 25.79$ \\
\hline 1.5 & $146.83 \pm 32.14$ \\
\hline 2 & $408.16 \pm 95.75$ \\
\hline
\end{tabular}

Data are presented as mean \pm standard division (SD)

kinins (KIN, BA, and TDZ) on some growth parameters and production of secondary metabolites and photosynthetic pigments in organ culture. The effect of different concentrations of the most effective type of cytokinin determined in this study was also evaluated. The results revealed that TDZ was the optimal type of growth regulator as compared to BA and KIN for in vitro

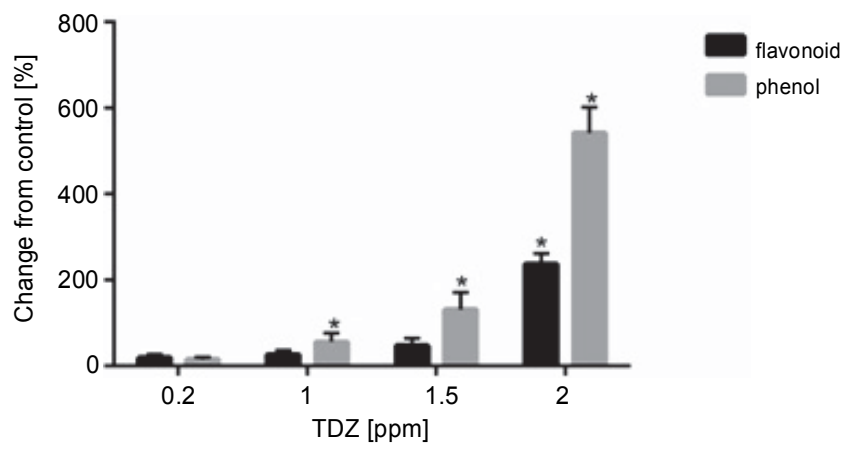

Fig. 6. Effect of different concentrations of TDZ on total flavonoid and phenol content $(P<0.05$ versus control)

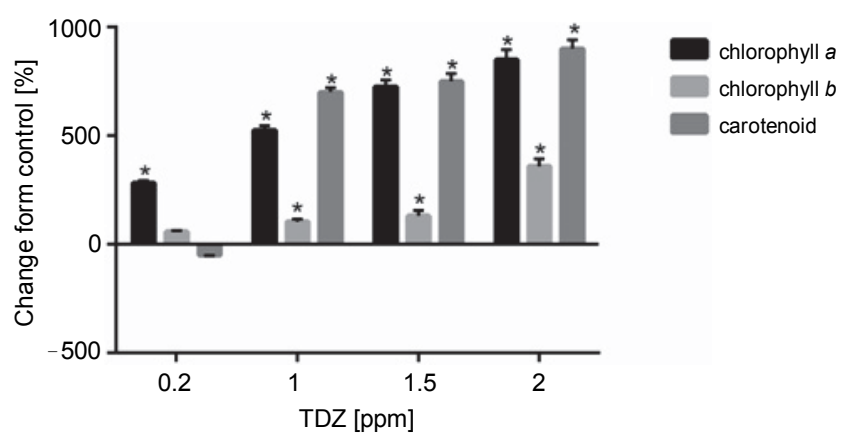

Fig. 7. Effect of different TDZ concentrations on photosynthetic pigments production $(P<0.05$ versus control)

cultures of $H$. officinalis, as it positively influenced the biochemical traits and pigmentation of the plant at its highest concentration of $2 \mathrm{ppm}$. Most growth parameters were not affected by any of the hormones tested, except for "number of leaves" and the "FW of explants" that were augmented in the presence of TDZ. The stimulating effect of TDZ on some growth parameters has also been reported in previous studies. In Clematis viticella and Clematis integrifolia, TDZ increased the number of leaves, nodes, and axillary shoots and the 
Table 9. Effect of different concentrations $(0,0.2,1,1.5$ and $2 \mathrm{ppm})$ of TDZ on total flavonoid (mg QE/g) and phenol (mg PYRO/g) content of Hyssopus officinalis L.

\begin{tabular}{c|c|c}
\hline $\begin{array}{c}\text { TDZ concentration } \\
{[\mathrm{ppm}]}\end{array}$ & $\begin{array}{c}\text { Flavonoid } \\
{[\mathrm{mg} \mathrm{QE} / \mathrm{g}]}\end{array}$ & $\begin{array}{c}\text { Phenol } \\
{[\mathrm{mg} \text { PYRO/g] }}\end{array}$ \\
\hline 0 & $42.25 \pm 0.10$ & $2.73 \pm 0.17$ \\
\hline 0.2 & $50.63 \pm 0.21$ & $3.15 \pm 0.08$ \\
\hline 1 & $53.63 \pm 0.10$ & $4.26 \pm 0.13$ \\
\hline 1.5 & $62.41 \pm 0.25$ & $6.33 \pm 0.12$ \\
\hline 2 & $142.56 \pm 0.10$ & $17.53 \pm 0.08$ \\
\hline
\end{tabular}

Data are presented as mean \pm standard division (SD)

Table 10. Effect of different concentrations $(0,0.2,1,1.5$ and $2 \mathrm{ppm})$ of TDZ on photosynthetic pigments production of Hyssopus officinalis L.

\begin{tabular}{c|c|c|c}
\hline $\begin{array}{c}\text { TDZ concentration } \\
{[\mathrm{ppm}]}\end{array}$ & $\begin{array}{c}\text { Chlorophyll } a \\
{[\mathrm{mg} / \mathrm{g}]}\end{array}$ & $\begin{array}{c}\text { Chlorophyll } b \\
{[\mathrm{mg} / \mathrm{g}]}\end{array}$ & $\begin{array}{c}\text { Carotenoid } \\
{[\mathrm{mg} / \mathrm{g}]}\end{array}$ \\
\hline 0 & $0.12 \pm 0.002$ & $0.22 \pm 0.001$ & $0.02 \pm 0.001$ \\
\hline 0.2 & $0.46 \pm 0.003$ & $0.35 \pm 0.002$ & $0.019 \pm 0.003$ \\
\hline 1 & $0.75 \pm 0.001$ & $0.45 \pm 0.001$ & $0.16 \pm 0.003$ \\
\hline 1.5 & $0.99 \pm 0.001$ & $0.51 \pm 0.003$ & $0.17 \pm 0.002$ \\
\hline 2 & $1.14 \pm 0.002$ & $1.01 \pm 0.001$ & $0.20 \pm 0.005$ \\
\hline
\end{tabular}

Data are presented as mean \pm standard division (SD)

weight of main shoots; however, it simultaneously decreased the length of main shoots and the weight of axillary shoots (Parzymies and Dabski, 2012). In Cassia angustifolia, TDZ was the optimal hormone for multiple shoot induction as compared to BA and KIN (Siddique et al., 2015). According to our results, the stimulation of growth and induction of shoots in TDZ-treated explants occurred only up to 30-35 days, and after this period, the growth rate of the regenerated plants decreased. Various reports have indicated that prolonged exposure to TDZ in a culture medium could negatively affect shoot proliferation or somatic embryogenesis. Liu et al. (2003) demonstrated that plants grown on TDZ-supplemented medium for 20 days produced the maximum number of shoots in Artemisia judaica, while there was no significant increase in the number of shoots when the duration of exposure was increased. Mondal et al. (1998) observed that the callus of tea plants grew slowly and developed necrotic lesions when explants were continuously grown on TDZ-containing medium. The deleterious effects of the continued presence of TDZ in the culture medium have also been reported for chickpea (Murthy et al., 1996), Pisum sativum (Böhmer et al., 1995), Anoectochilus formosanus (Ket et al., 2004), and Rauvolfia tetraphylla and Psoralea corylifolia (Faisal and Anis, 2006). According to previous reports, the optimal TDZ exposure duration is $15-25$ days, and the subsequent transfer to TDZ-free medium is beneficial to obtain better results (Lorteau et al., 2001; Makara et al., 2010). As TDZ is a urea-based cytokinin, it is nondegradable by cytokinin oxidase and is persistent in plant tissues. Makara et al. (2010) reported that TDZ had a carry-over effect that enabled shoots to continue proliferation on a hormone-free medium. Although the exposure duration of TDZ is an important factor for its inhibitory effects on growth parameters, the concentration of the hormone in the medium also plays a critical role in these phenomena. One of the reasons for the deleterious effect of TDZ may be related to the accumulation of endogenous ethylene in plant tissues (Lorteau et al., 2001). The negative influence of ethylene on growth parameters has been reported in Oryza sativa (Ma et al., 2014), Arabidopsis thaliana (Swarup et al., 2007), Achillea millefolium and Rumex palustris (Visser 
and Pierik, 2007), and Linum usitatissimum (Mundhara and Rashid, 2006).

The effect of TDZ on secondary metabolite production in in vitro culture conditions is also well documented. In our experiment, we observed a positive correlation between the content of total phenolics and flavonoids with TDZ concentration in the medium. Baskaran et al. (2012) showed the high level production of secondary metabolites in root culture of Merwilla plumbea in the presence of TDZ. The maximum level of total phenolic content in callus cultures of Artemisia absinthium was also obtained in response to $1.0 \mathrm{mg} / \mathrm{l}$ of TDZ (Ali et al., 2013). It was suggested that TDZ might have triggered stress in plant tissues, following which the phenylpropanoid pathway was activated to produce different secondary metabolites to resist the stress conditions (Bhargava et al., 2013). Although the mechanism of action of TDZ is not clearly understood at the molecular level, there is evidence demonstrating variations in gene expression in the presence of this hormone. The expression of laccase $(R h L A C)$ and aquaporin $(R h T I P)$ genes in Sparkle rose plants was not affected by TDZ (Rasouli et al., 2015); however, several abscission-related genes in Gossypium hirusutum plants (GhCEL1, GhPG, and $G h A C S$ ) were significantly upregulated (Du et al., 2014), and the nitrate transporter genes (AtNRT2.1 and AtNRT2.3) were downregulated in TDZ-treated $A$. thaliana plants (Kiba et al., 2005).

The effect of different concentrations of TDZ on the production of photosynthetic pigments was also investigated in the present study. The results showed that the amount of chlorophyll $a$, chlorophyll $b$, and carotenoids significantly increased following increased TDZ concentrations. These results are in agreement with those of Rayya et al. (2015) who found that cytokinin improved the efficiency of photosynthetic machinery and thus enhanced the content of photosynthetic pigments. It has been reported that the elevated level of photosynthetic pigments in the presence of cytokinin may be related to the cell division/expansion-promoting effect of TDZ, which subsequently increases the size and number of chloroplasts (Murthy et al., 1998; Amarante et al., 2003). Yaronskaya et al. (2006) reported that cytokinin could stimulate the production of photosynthetic pigments in barely seedlings by accelerating the biosynthesis of 5 -aminolevulinic acid (ALA), which is considered as the precursor of tetrapyrrole.

\section{Conclusions}

On the basis of the present study, it can be concluded that TDZ provides the best results compared to KIN and BA in organ culture of $H$. officinalis plants, leading to an increase in the production of secondary metabolites, photosynthetic pigmentation, and growth properties. Further studies are needed to investigate the effect of different combinations of cytokinins as well as a cytokinin and an auxin to enhance further medicinal properties of this important plant.

\section{Acknowledgments}

The authors would like to extend their sincere appreciation to the "Hayyan Foundation" at University of Tabriz for technical support. This work was supported by the University of Tabriz under Grant no.: 12238/4389.

\section{References}

Ali M., Abbasi B.H., Ihsa-ul-haq (2013) Production of commercially important secondary metabolites and antioxidant activity in cell suspension cultures of Artemisia absinthium L. Indust. Crops Prod. 49: 400-406.

Amarante C.V.T.A., Megguer C.A., Blum L.E.B. (2003) Effect of preharvest spraying with thidiazuron on fruit quality and maturity of apples. Rev. Brasil. Fruticult. 25(1): 59-62.

Anand U., Jacobo-Herrera N., Altemimi A., Lakhssassi N. (2019) A comprehensive review on medicinal plants as antimicrobial therapeutics: potential avenues of biocompatible drug discovery. Metabolites 9: 258-271. doi: 10.3390/metabo 9110258

Baskaran P., Ncube B., Van Staden J. (2012) In vitro propagation and secondary product production by Merwilla plumbea (Lindl.) Speta. Plant Growth Regul. 67(3): 235-245.

Bernáth J. (1993) Introduction and cultivation of traditional and new medicinal and aromatic plant crops in Hungary. International Symposium on Medicinal and Aromatic Plants. Acta Hortic. 344: 238-248. doi: 10.17660/acta hortic. 1993.344 .28

Bhargava A., Clabaugh I., To J.P., Maxwell B.B., Chiang Y.H., Schaller E.G. et al. (2013) Identification of cytokinin responsive genes using microarray meta-analysis and RNA-seq in Arabidopsis thaliana. Plant Physiol. 162(1): 272-294. doi: $10.1104 /$ pp.113.217026

Böhmer P., Meyer B., Jacobsen H.J. (1995) Thidiazuron-induced high frequency of shoot induction and plant regeneration in protoplast derived pea callus. Plant Cell Rep. 15(1-2): 26-29.

Chitra J., Shivani K., Rekha V. (2019) Bioactivity of secondary metabolites of various plants: a review. Int. J. Pharm. Sci. Res. 10(2): 494-504.

Du M., Li Y., Tian X., Duan L., Zhang M., Tan W. et al. (2014) The phytotoxin coronatine induces abscission-related gene expression and boll ripening during defoliation of cotton. PloS one 9(5): e97652. 
Faisal M., Anis M. (2006) Thidiazuron induced high frequency axillary shoot multiplication in Psoralea corylifolia. Biol. Plant. 50(3): 437-440.

Fathiazad F., Hamedeyazdan S. (2011) A review on Hyssopus officinalis L.: composition and biological activities. Afr. J. Pharm. Pharmacol. 5(17): 1959-1966. doi: 10.5897/ AJPP11.527

Gupta S.K., Liu R.B., Liaw S.Y., Chan H.S., Tsay H.S. (2011) Enhanced tanshinone production in hairy roots of "Salvia miltiorrhiza Bunge" under the influence of plant growth regulators in liquid culture. Bot. Stud. 52(4): 435-443.

Ket N., Hahn E., Park S., Chakrabarty D., Paek K. (2004) Micropropagation of an endangered orchid Anoectochilus formosanus. Biol. Plant. 48(3): 339-344.

Khan M.A., Abbasi B.H., Shinwari Z.K. (2014) Thidiazuron enhanced regeneration and silymarin content in Silybum marianum L. Pak. J. Bot. 46(1): 185-190.

Kiba T., Naitou T., Koizumi N., Yamashino T., Sakakibara H., Mizuno T. (2005) Combinatorial microarray analysis revealing Arabidopsis genes implicated in cytokinin responses through the His $\rightarrow$ Asp phosphorelay circuitry. Plant Cell Physiol. 46(2): 339-355.

Liu C., Murch S., El-Demerdash M., Saxena P. (2003) Regeneration of the Egyptian medicinal plant Artemisia judaica $L$. Plant Cell Rep. 21(6): 525-530.

Lorteau M.A., Ferguson B.J., Guinel F.C. (2001) Effects of cytokinin on ethylene production and nodulation in pea (Pisum sativum) cv. Sparkle. Physiol. Plant. 112(3): 421-428.

Ma B., Yin C.C., He S.J., Lu X., Zhang W.K., Lu T.G. et al. (2014) Ethylene-induced inhibition of root growth requires abscisic acid function in rice (Oryza sativa L.) seedlings. PLoS Genet. 10(10): e1004701.

Makara A., Rubaihayo P., Magambo M. (2010) Carry-over effect of Thidiazuron on banana in vitro proliferation at different culture cycles and light incubation conditions. Afr. J. Biotech. 9(21): 3079-3085.

Mondal T.K., Bhattacharya A., Sood A., Ahuja P.S. (1998) Micropropagation of tea (Camellia sinensis (L.) O. Kuntze) using Thidiazuron. Plant Growth Reg. 26(1): 57-61.

Mundhara R., Rashid A. (2006) TDZ-induced triple-response and shoot formation on intact seedlings of Linum, putative role of ethylene in regeneration. Plant Sci. 170(2): 185-190.

Murashige T., Skoog F. (1962) A revised medium for rapid growth and bio assays with tobacco tissue cultures. Physiol. Plant. 15(3): 473-497.
Murthy R., Dougherty P.M., Zarnoch S.J., Allen H.L. (1996) Effects of carbon dioxide, fertilization, and irrigation on photosynthetic capacity of loblolly pine trees. Tree Physiol. 16(6): 537-546.

Murthy B., Murch S., Saxena P.K. (1998) Thidiazuron: a potent regulator of in vitro plant morphogenesis. In vitro Cell. Develop. Biol. Plant 34(4): 267.

Parzymies M., Dabski M. (2012) The effect of cytokinin types and their concentration on in vitro multiplication of Clematis viticella (L.) and Clematis integrifolia Petit Faucon. Acta Sci. Pol. Hort. Cult. 11(1): 81-91.

Pourebad N., Motafakkerazad R., Kosari-Nasab M., Farsad Akhtar N., Movafeghi A. (2015) The influence of TDZ concentrations on in vitro growth and production of secondary metabolites by the shoot and callus culture of Lallemantia iberica. Plant Cell Tissue Organ Cult. 122(2): 331-339.

Rasouli O., Ahmadi N., Behmanesh M., Nergi M.D. (2015) Effects of $B A$ and $T D Z$ on postharvest quality and expression of laccase and aquaporin genes in cut rose "Sparkle". South Afr. J. Bot. 99: 75-79.

Rayya A., Nabila E., El-Sheikh M. (2015) Vegetative growth of Manzanillo and Picual olive cultivars as Affected by irrigation with saline water. Int. J. ChemTech Res. 8(10): 33-38.

Siddique I., Bukhari N.A.W., Perveen K., Siddiqui I. (2015) Influence of plant growth regulators on in vitro shoot multiplication and plantlet formation in Cassia angustifolia Vahl. Brazil. Arch. Biol. Technol. 58(5): 686-691.

Swarup R., Perry P., Hagenbeek D., Van Der Straeten D., Beemster G.T. et al. (2007) Ethylene upregulates auxin biosynthesis in Arabidopsis seedlings to enhance inhibition of root cell elongation. Plant Cell 19(7): 2186-2196.

Visser E.J., Pierik R. (2007) Inhibition of root elongation by ethylene in wetland and non wetland plant species and the impact of longitudinal ventilation. Plant Cell Environ. 30(1): 31-38.

Wellburn A.R. (1994) The spectral determination of chlorophylls a and $b$, as well as total carotenoids, using various solvents with spectrophotometers of different resolution. J. Plant Physiol. 144(3): 307-313.

Yaronskaya E., Vershilovskaya I., Poers Y., Alawady A.E., Averina N., Grimm B. (2006) Cytokinin effects on tetrapyrrole biosynthesis and photosynthetic activity in barley seedlings. Planta 224(3): 700-709. 